\title{
Perhitungan Numerik Rapat Keadaan Graphene Monolayer Menggunakan Metode Newton Raphson
}

\author{
Ilham Pebrika', Iman Santoso ${ }^{2}$ \\ ${ }^{1}$ Jurusan Fisika, Fakultas Matematika dan Ilmu Pengetahuan Alam, \\ ${ }^{1,2}$ Universitas Gadjah Mada, Yogyakarta 55281, Indonesia \\ 1,2 ilham.pebrika@mai.ugml.ac.id,iman.santoso@ugm.ac.id
}

\begin{abstract}
Abstrak -. Telah dilakukan perhitungan secara numerik terhadap rapat keadaan pada graphene layer tunggal. Rapat keadaan dihitung berdasarkan persamaan energi dispersi $E(k)$ pada energi rendah. Pada umumnya rapat keadaan dihitung secara numerik menggunakan persamaan $N(E)=N_{f} \sum_{k} \delta(E-E(k))$, yakni ketika posisi $\varepsilon=E(k)$ dengan $N_{f}$ merupakan faktor degenerasi. Nilai $N(E)$ dikelompokan berdasarkan nilai-nilai yang hampir sama yang kemudian dijumlahkan menjadi nilai rapat keadaan. Hanya saja metode ini memiliki ralat yang lebih besar karena nilai $N(\varepsilon)$ yang diperoleh dianggap sama dengan nilai yang terdekat. Pada kajian ini nilai rapat keadaan dihitung dengan metode yang berbeda yakni mengimplementasikan nilai $\varepsilon=E(k)$ tetapi dengan pendekatan nilai yang mendekati nilai yang sebenarnya. Nilai tersebut direpresentasikan dengan nilai akar-akar dari persamaan energi dispersi dikurangi nilai level energi $\mathrm{E}$ sebegai fungsi pembuat nol $(E(k)-E)$. Nilainya dapat dihitung dengan metode newton-raphson. Nilai akar ini kemudian diidentifikasikan dengan nilai 1 dan dijumlahkan per level energi $E$ sehingga setiap levelnya memiliki nilai rapat keadaan yang telah dijumlahkan berdasarkan banyak akar yang ada. Dari perhitungan rapat keadaan menggunakan metode newton-raphson diperoleh nilai yang sama dengan perhitungan yang telah dilakukan sebelumnya.
\end{abstract}

Kata kunci : Graphene,Rapat Keadaan, Newton-Raphson,

\begin{abstract}
The Numerical Computation of Density Of States of Graphehe Monolayer has been carried out. Calculation of Density of States (DOS) based on energy dispersion $E(k)$ at low energy. Generally calculation of DOS using numerically methods using $N(E)=N_{f} \sum_{k} \delta(E-E(k))$ equation, that at $\varepsilon=E(k)$ with $N f$ is factor of degeneration. The values of $N(E)$ has been included in nearly equall values and has been summed be a DOS. This method be possessed of large errors because the values of $N(E)$ acquired same with closest values. In this study the values of DOS is calculated using different method that is implementation of true values. It can be represented using the values ot root from energy dispersion minus values of level energy be a zero maker equation $(E(k)-E)$. it can be calculated using Newton-Raphson method. Next the values of root is identified by one unit and summed per level energy $E$, with the result that every level be possessed of DOS based by summing all roots.
\end{abstract}

Keywords: Graphene, Density of States, Newton-Raphson,

\section{PENDAHULUAN}

Graphene yang merupakan material karbon dua dimensi dengan struktur atom heksagonal yang berhasil diisolasi oleh Konstantin Novoselov dan Andre Geim pada tahun $2004^{(1)}$. Salah satu kajian yang diteliti pada material graphene ialah rapat Keadaan atau Density of State (DOS) yang merupakan gambaran tentang keadaan (States) pada tiap level energi ${ }^{(2)}$. Nilai DOS dapat diperoleh dari penurunan nilai energi dispersi $\mathrm{E}(\mathrm{k})$ yakni $^{(2)}$ :

$$
\overrightarrow{E_{ \pm}}= \pm t \sqrt{(3+f(\vec{k}))}+t^{\prime} f(\vec{k}),
$$

Dengan $f \vec{k}$

$$
f(\vec{k})=2 \cos \left(\sqrt{3} k_{y} a\right)+4 \cos \left(\frac{\sqrt{3}}{2} k_{y} a\right) \cos \left(\frac{3}{2} k_{x} a\right),
$$
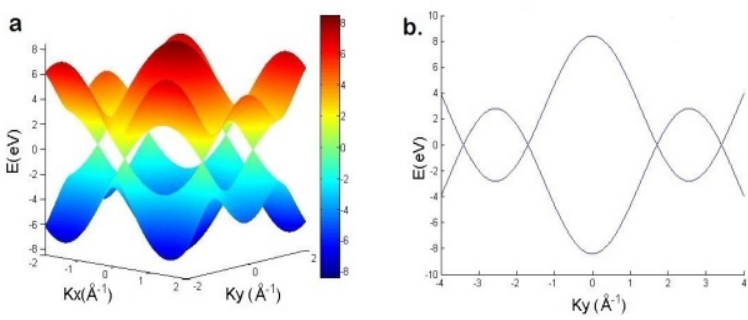

Gambar.1 Grafik energi dispersi (a) untuk nilai $t \approx 2.8$ dan $\mathbf{t}^{\prime}=0$ (b) energi dispersi untuk nilai $\mathbf{K x}=\mathbf{0}$

Energi dispersi diperoleh dari metode Tight ikatan kuat (Tight Binding) yaitu model pendekatan untuk menghitung struktur pita elektronik pada sistemyang digunakan dengan memperkirakan kumpulan pita berdasarkan fungsi gelombang sebagai superposisi fungsi gelombang atom yang terisolasi pada kisi kisi gelombang

${ }^{(3)}$.Dengan mempertimbangkan elektron yang berpindah ke atom terdekat maupun ke atom terdekat berikutnya dapat dituliskan (dengan $\hbar=1)^{(2)}$ 


$$
H=-t \sum_{<i, j>, \sigma}\left(a_{\sigma i}^{\dagger} b_{\sigma j}^{\dagger}+H . c\right)-t^{\prime} \sum_{<i, j>, \sigma}\left(a_{\sigma i}^{\dagger} a_{\sigma j}^{\dagger} b_{\sigma i}^{\dagger} a_{\sigma j}^{\dagger}+H . c\right),
$$

Merupakan persamaan halmitonan graphene dimana $a_{\sigma i}\left(a_{\sigma i}^{\dagger}\right)$ lengan spin $\sigma(\sigma=\uparrow, \downarrow)$ merupakan operator penghancur (kreasi) di titik $\vec{R}_{i}$ pada sub kisi A (defenisi yang sama untuk $B)$. dengan nilai parameter $\mathrm{t} \approx 2.8 \mathrm{eV})$ diperoleh persamaan energi dispersi. ${ }^{(2)}$

Kajian terhadap nilai DOS telah banyak dilakukan baik secara analitik maupun secara numerik. Castro Neto ${ }^{(2)}$ misalnya menghitung nilai DOS secara analitik pada graphene monolayer dengan memvariasikan parameter lompatan atom (Hopping Parameter) $t$ dan $t^{\prime}$ dimana nilai $t$ merupakan nilai lompatan untuk atom terdekat dan $t^{\prime}$ adalah nilai lompatan atom terdekat selanjutnya. Pada perhitungan tersebut diperoleh nilai SVH yang berada pada nilai $\pm 1 \mathrm{eV}^{(2)}$. Nilai yang sama juga diperoleh oleh $\mathrm{Nicol}^{(3)}$

Pada umumnya rapat keadaan dihitung secara numerik menggunakan persamaan ${ }^{(3)}$

$$
N(\varepsilon)=N_{f} \sum_{k} \delta(\varepsilon-E(k))
$$

yakni ketika posisi $E=E(k)$ dimana nilai selisihnya sama dengan nol. $N_{f}$ merupakan faktor degenerasi kemudian nilai-nilai $N(E)$ dikelompokan berdasarkan nilai-nilai yang memiliki nilai-nilai yang hampir sama, misal nilai akar-akar yang diperoleh adalah 1.85, 1.9, 2, 2,1 dan 2.15. Nilai-nilai ini dikelompokan kedalam nilai 2 sehingga berjumlah lima untuk menjadi jumlah nilai rapat keadaan pada level energi $(E)$ tersebut. Dari metode yang digunakan akan terlihat bahwa nilai yang dihasilkan akan memilki nilai ralat yang cukup besar dikarenakan nilai-nilai yang ada dianggap sama dengan nilai yang terdekat sehingga memiliki selisih berdasarkan nilai rentang pengelompokan nilai-nilai tersebut, misal untuk kasus diatas nilai dua berkisar antara nilai 1,8-2,15 sahingga nilai ralat memiliki rentang sebesar \pm 0 , 35. Atas dasar inilah untuk tinjauan pada skripsi ini digunakan metode yang lebih akurat yakni mengimplementasikan nilai $\varepsilon=E(k)$ tetapi dengan pendekatan nilai yang mendekati nilai yang sebenarnya. Nilai tersebut dapat direpresentasikan dengan nilai akarakar dari persamaan energi dispersi dikurangi dengan nilai level energi $E$. Salah satu metode yang bisa digunakan adalah metode Newton-Raphson(NR).

Penggunaan metode pencarian nilai akar, Newton-Raphson. dikarenakan untuk menghitung nilai akar-akar pada netode NR hanya membutuhkan satu nilai tebakan awal, sehingga nilai tebakan awal bisa dibuat pada rentang nilai tertentu karena setiap nilai akan dianggap sebagai nilai tebakan awal. Sejauh ini penulis belum menemukan metode perhitungan rapat-keadaan mengimplementasikan metode NR.

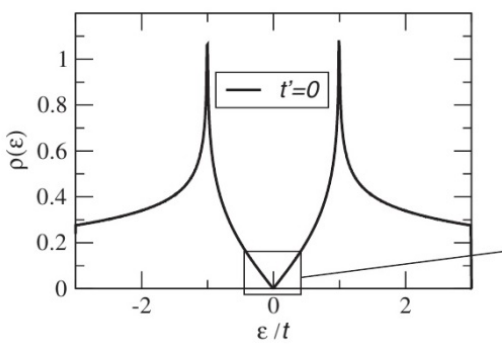

Gambar.2 Hasil DOS yangdihitung secara analitik oleh Neto ,dkk. ${ }^{(2)}$

\section{METODE PENELITIAN}

Metode penentuan nilai akar-akar NewtonRaphson (NR) . Metode NR merupakan salah satu metode untuk menentukan akar akar suatu persamaan.Metode NR menggunakan satu nilai tebakan awal yakni nilai perkiraan awal dari akar akar persamaan yang ingin dihitung $x i$. Suatu garis singgung dapat dibuat dari titik (xi,f(xi), dimana garis singgung tersebut memotong sumbu $\mathrm{x}$ yang biasanya memberikan perkiraan yang lebih dekat dengan nilai akar. Dasar dari persamaan ini adalah Aproksimasi linear dari fungsi disekitar nilai akar. nilainya bisa diperoleh dengan memperluas fungsi $f(x r=0)$ disekitar nilai akar xr melalui ekspansi Taylor $(5)(6)(7)$.

$$
x_{i+1}=x_{i}-\frac{f\left(x_{i}\right)}{f^{\prime}\left(x_{i}\right)} .
$$

Pada metode NR yang dipakai pada perhitungan di skripsi ini nilai pembuat nol diberikan oleh nilai $E(k)$ (sby) sebagai level energi pada grafik Energi dispersi terhadap nilai $K x$ dan $K y$ sehingga persamaannya menjadi

$$
x_{i+1}=x_{i}-\frac{E\left(\vec{x}_{i}\right)-E}{E^{\prime}\left(\vec{x}_{i}\right)} .
$$

Bagan alir untuk menghitung DOS dari Energi $E(K)$ menggunakan metode newton raphson

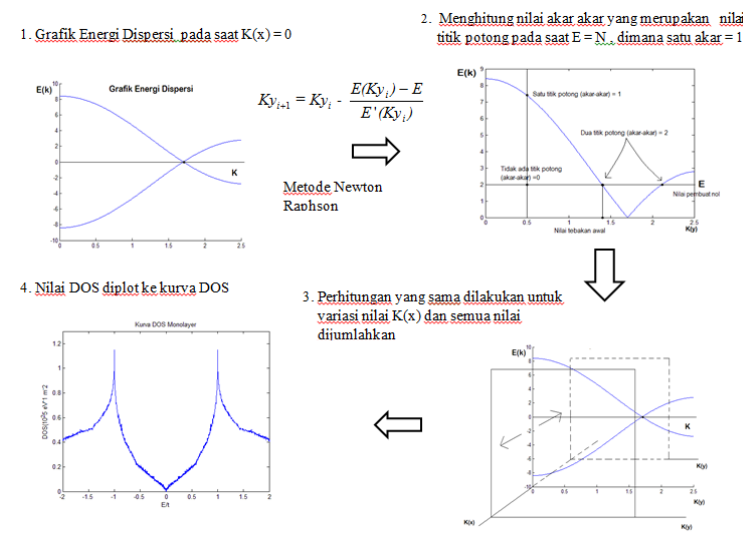

Gambar 4 Bagan alir ekstraksi DOS dari Energi Dispersi $(\mathbf{E}(\mathbf{K}))$ 


\section{HASIL DAN PEMBAHASAN}

Hasil perhitungan secara numerik menggunakan metode Newton-Raphson memberikan hasil :
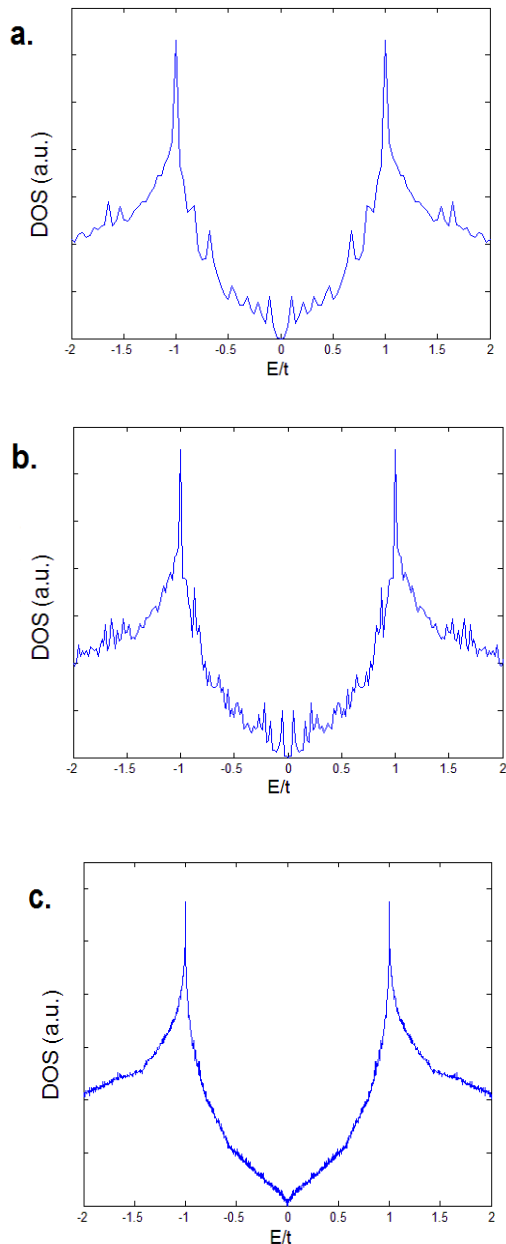

Gambar.3 Beberapa bentuk grafik DOS monolayer graphene dengan beberapa variasi parameter komputasi (a) $\Delta K x=0.05 \Delta E=0.1 \quad \Delta K y=0.1$ (b) $\Delta K x=0.1 \Delta E=0.05 \Delta K y=0.1$ (c) $\Delta K x=0.05 \Delta E=0.05 \Delta K y=0.1$

Dalam perhitungan ini yang menggunakan beberapa parameter numerik diperoleh hasil yang bervariasi untuk setiap parameter Perhitungan numerik untuk menghitung nilai DOS pada graphene monolayer didasarkan pada persamaan energi dispersi $E(k)$ (Persamaan 1), menggunakan metode Newton Raphson yang menghasilkan beberapa grafik DOS dengan beberapa variasi parameter numerik. Parameter-parameter tersebut yakni,parameter level energi $(E)$ parameter $K(x)$, parameter tebakan awal $(K(y))$ dan iterasi $(n)$. Untuk variasi parameter tebakan awal $K(y)$ dan nilai iterasi $(n)$ tidak memberikan pengaruh yang terlalu berarti terhadap nilai bentuk grafik yang dihasilkan.

Untuk variasi parameter tebakan awal $K(y)$ juga tidak memberikan perubahan pada hasil grafik hal ini karena nilai tebakan awal yang merupakan nilai predisksi akar-akar yang sebenarnya sehingga nilai tersebut akan mengacu pada nilai-nilai akar sebenarnya dari persamaan. Jika nilainya tidak ada atau jauh dari nilai akar-akar yang ada maka nilai prediksi akar dari tebakan awal dianggap nol. Sedangkan untuk parameter iterasi $(n)$ juga diperoleh hasil grafik yang sama untuk beberapa variasi parameter iterasi $(n)$. Hal ini dikarenakan faktor kekonvergenan dari fungsi yang digunakan (energi dispersi $E(k)$. Dimana nilai akan mencapai nilai konvergen untuk pengulangan iterasi yang tidak terlalu lama. Nilai iterasi $(n)$ yang diberikan dengan jumlah 50, 100, 300, 500 dan 1000, menghasilkan grafik yang sama.

Walaupun tidak memberikan pengaruh pada hasil grafik DOS, parameter tebakan awal $K(y)$ maupun parameter iterasi $(n)$ tetap memberikan pengaruh pada proses lamanya perhitungan yakni jika nilai iterasi $(n)$ dan parameter tebakan awal $K(y)$ yang diberikan semakin besar maka waktu untuk proses perhitungan akan bertambah karena setiap proses perhitungan program akan menghitung nilai yang lebih banyak sehingga membutuhkan waktu yang lebih lama untuk masuk ke perhitungan selanjutnya.
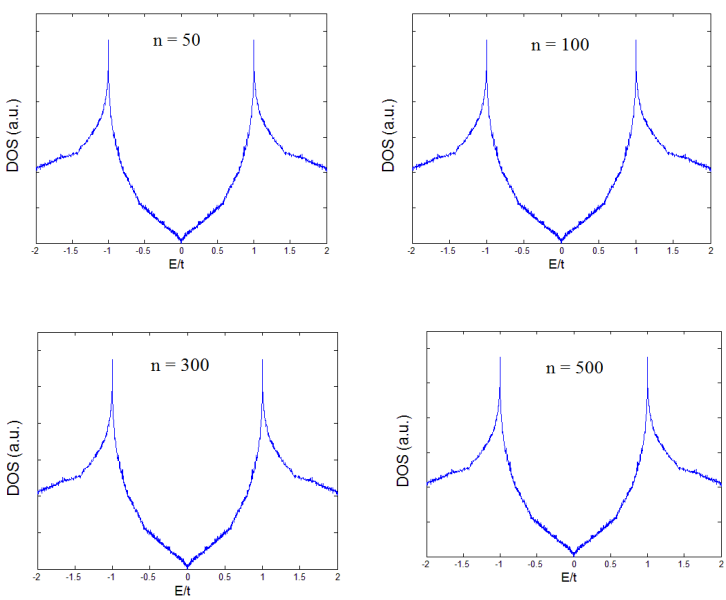

Gambar.4 Beberapa bentuk grafik DOS untuk variasi $\mathrm{n}=\mathbf{5 0}, \mathrm{n}=\mathbf{1 0 0}, \mathrm{n}=\mathbf{3 0 0}$, dan $\mathrm{n}=\mathbf{5 0 0}$

Dari perhitungan yang diperoleh menggunakan metode Newton Rapson diperoleh hasil DOS yang sama dengan perhitungan sebelumnya yang dilakukan oleh Neto dkk menggunakan metode analitik maupun numerik $^{(2)(3)}$

\section{KESIMPULAN}

1. Metode Newton Raphson digunakan sebagai salah satu metode untuk menghitung nilai DOS berdasarkan persamaan Energi Dispersi $E(k)$. Faktor yang paling berpengaruh terhadap hasil grafik yang dihasilkan adalah parameter $E$ dan $K(x)$, di mana semakin besar nilainya (nilai partisi $\Delta E$ dan $\Delta K(x)$ semakin kecil) maka grafik yang dihasilkan akan semakin baik.

2. Pola linear yang terbentuk pada DOS dijelaskan dari persamaan energi dispersi dimana terbentuk garis 
linear di sekitar tenaga nol. Nilai ini terbentuk karena adanya keterlibatan Dirac Fermions yang memiliki dispersi energi yang menyerupai dispersi energi partikel-partikel ultrarelativistik sehingga membentuk pola linear. Pola linear ini juga dapat dijelaskan dari persamaan energi Fermi (Fermi Energy), di mana berdasarkan persamaan persamaan $E f=h v f k$ di mana nilai energi akan sebanding dengan nilai $(k)$ dan energi fermi sehingga dapat menjelaskan pola linear. Sedangkan untuk pola logaritmik bisa dijelaskan dari posisi flat(datar) pada pita dispersi atau pada posisi saddle Point

\section{PUSTAKA}

[1] Novoselov, K. S., 2011,Nobel Lecture:Graphene: Materials in the Flatland, Rev. Mod. Phys. 83, 837838.

[2] Neto, Castro, A. H. Guinea, F., N. M. R. Novoselov, K.S. and Geim, A. K.,2009, The Electronic Properties of Graphene, Rev. Mod. Phys., 81, 109162.

[3] Tabert, C. J. and Nicol, E. J., 2012,Dynamical Conductivity of AA-Stacked Bilayer Graphene, Phys. Rev. B, 86, 075439.

[4] Manaf, M. N., Santoso, I., and Hermanto, A., 2014,Density of states of Twisted bilayer graphene at Low Energy, Procedding of Confeerence on Phys(ICP 2014), 19-21.

[5] Tresnaningsih, Rizky, 2010,Modul Mata Kuliah Analisis Numerik, FMIPA, IKIP PGRI. Madiun.

[6] Pang, Tao, 2006,An Introduction Computational Physiscs, Second Edition, Cambridge University Press, UK.

[7] Pujiyanta, Ardi, 2007 Komputasi Numerik dengan Matlab, Graha Ilmu, Yogyakarta 